\title{
Correction: Anti-Müllerian hormone and Inhibin B after stem cell transplant in childhood: a comparison of myeloablative, reduced intensity and treosulfan-based chemotherapy regimens
}

\author{
Alison Leiper (D) - Maite Houwing • E. Graham Davies • Kanchan Rao • Siobhan Burns • Emma Morris $\mathbb{D}$ - Joop Laven • \\ Anne-Lotte van der Kooi - Marry van den Heuvel Eibrink · Stephen Nussey
}

Published online: 24 April 2020

(c) The Author(s), under exclusive licence to Springer Nature Limited 2020

Correction to: Bone Marrow Transplantation

https://doi.org/10.1038/s41409-020-0866-9

published online 30 March 2020

The original version of this Article contained errors in the footnote of Table 1 .

The footnote was incorrectly published as:

${ }^{\mathrm{a}, \mathrm{b}}$ Not yet reached puberty.
${ }^{\mathrm{c}}$ Failed pubertal progression.

Instead, the correct footnote should read:

${ }^{\mathrm{a}} 4$ males not yet reached puberty.

${ }^{\mathrm{b}} 1$ male not yet reached puberty.

${ }^{\mathrm{c}} 1$ female entered puberty spontaneously but failed to progress later requiring HRT.

This has now been corrected in both the PDF and HTML versions of the Article. 